This information is current as of April 26, 2023.

Super-Resolution Track Density Imaging: Anatomic Detail versus Quantification

F. Calamante

AJNR Am J Neuroradiol 2016, 37 (6) 1066-1067

doi: https://doi.org/10.3174/ajnr.A4721

http://www.ajnr.org/content/37/6/1066 


\section{Super-Resolution Track Density Imaging: Anatomic Detail versus Quantification}

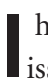
have read with great interest the article by Hoch et al, ${ }^{1}$ in this issue of the American Journal of Neuroradiology describing an MR imaging protocol to discriminate the internal anatomy of the human brain stem. Their study provides a very nice illustration of one of the key strengths of MR imaging, in which multiple MR imaging contrast mechanisms/parameters can complement each other and provide an enhanced visualization of brain structures. In this particular study, the synergy of a recently proposed echo modulation curve (EMC) method for T2 mapping ${ }^{2}$ and the super-resolution track density imaging (TDI) method $^{3}$ is shown to visualize many of the tracts and nuclear groups within the brain stem, to a level not previously shown before with in vivo 3T MR imaging. Most important, this combined protocol was achieved with a total acquisition time that is feasible for clinical investigations (though it relies on postprocessing methods that may be, so far, available only at large specialized centers, a limitation likely to be overcome in the future, with the widespread use of these methodologies).

The results of the study by Hoch et $\mathrm{al},{ }^{1}$ demonstrating the synergy of TDI with other MR imaging parameters to achieve enhanced anatomic delineation are consistent with the findings from previous studies, such as the combination of super-resolution TDI and ultra-high-field T1-weighted images to delineate the substructures of the thalamus at 7T MR imaging. ${ }^{4}$

A related issue, also briefly mentioned in the article by Hoch et $\mathrm{al},{ }^{1}$ is that of quantification. While T2 is a well-studied parameter and one that has been used quantitatively for clinical applications in the past (eg, in epilepsy, ${ }^{5}$ Friedreich ataxia, ${ }^{6}$ and multiple sclerosis, ${ }^{7}$ among others), quantification of TDI has been the subject of recent controversy, with some studies reporting successful clinical applications $s^{8-10}$ and others emphasizing its potential limitations for quantitative studies. ${ }^{11-14}$

The super-resolution TDI method was initially developed primarily as a qualitative imaging method with high anatomic contrast. ${ }^{3}$ Despite its potential role as a quantitative parameter for fiber-density mapping (given that TDI is a measure of the density of streamlines from fiber tracking), recent studies have highlighted its limitations as a fully quantitative parameter, including relatively low quantitative reproducibility ${ }^{12}$ and sensitivity to detecting false-positives and false-negatives. ${ }^{14}$

Given these limitations, it could be argued that the power of super-resolution TDI is not as a quantitative tool but rather in the high anatomic contrast and detail it provides (as illustrated by the results from Hoch et al, ${ }^{1}$ and other related studies $\left.{ }^{3,4,15,16}\right)$. Quantification is therefore better performed on the basis of, for example, other complementary track-based parameters, such as track-weighted apparent diffusion coefficient (TW-ADC), trackweighted fractional anisotropy (TW-FA), and track-weighted fiber-orientation distribution (TW-FOD), ${ }^{12,17}$ or even on the basis of other properties of the streamlines themselves (such as their lengths in the average pathlength map $[\mathrm{APM}]$ method $)^{13}$ or on measures of the voxelwise fiber-orientation distribution (such as those related to the apparent fiber density [AFD] method). ${ }^{14,18}$ While these maps have reduced anatomic contrast relative to that seen in TDI maps, they have more reliable quantitative proper$\operatorname{ties}^{12,13}$ and are therefore more suitable for quantitative analysis in clinical applications.

In this context, one could envisage a scenario in which the protocol proposed by Hoch et $\mathrm{al}^{1}$ is used to identify and delineate the structures of interest (eg, specific tracts and nuclear groups within the brain stem, as in Figs 2-8 in that study), but then these other complementary parameters are used for quantification within those specific structures. Thus, some maps (eg, EMC and super-resolution TDI) are used to define the structures of interest (on the basis of their high anatomic contrast and detail), while other maps (eg, TW-ADC, TW-FA, TW-FOD, APM, total AFD, and so forth) are used to provide more reliable quantitative measures. This approach, in turn, emphasizes once again the strength in the synergy of multiple MR imaging parameters or as Aristotle once said, "The whole is greater than the sum of its parts."

\section{REFERENCES}

1. Hoch MJ, Chung S, Ben-Eliezer N, et al. New clinically feasible 3T MRI protocol to discriminate internal brain stem anatomy. AJNR Am J Neuroradiol 2016 Feb 11. [Epub ahead of print] CrossRef Medline

2. Ben-Eliezer N, Sodickson DK, Block KT. Rapid and accurate T2 
mapping from multi-spin-echo data using Bloch-simulation-based reconstruction. Magn Reson Med 2015;73:809-17 CrossRef Medline

3. Calamante F, Tournier JD, Jackson GD, et al. Track density imaging (TDI): super-resolution white matter imaging using whole-brain track-density mapping. Neuroimage 2010;53:1233-43 CrossRef Medline

4. Calamante F, Oh SH, Tournier JD, et al. Super-resolution trackdensity imaging of thalamic substructures: comparison with highresolution anatomical magnetic resonance imaging at 7.0T. Hum Brain Mapping 2013;34:2538-48 CrossRef Medline

5. Jackson GD, Connelly A, Duncan JS, et al. Detection of hippocampal pathology in intractable partial epilepsy: increased sensitivity with quantitative magnetic resonance T2 relaxometry. Neurology 1993; 43:1793-99 CrossRef Medline

6. Bonilha da Silva C, Bergo FP, D'Abreu A, et al. Dentate nuclei T2 relaxometry is a reliable neuroimaging marker in Friedreich's ataxia. Eur J Neurol 2014;21:1131-36 CrossRef Medline

7. Bonnier G, Roche A, Romascano D, et al. Advanced MRI unravels the nature of tissue alterations in early multiple sclerosis. Ann Clin Transl Neurol 2014;1:423-32 CrossRef Medline

8. Ziegler E, Rouillard M, André E, et al. Mapping track density changes in nigrostriatal and extranigral pathways in Parkinson's disease. Neuroimage 2014;99:498-508 CrossRef Medline

9. Barajas RF Jr, Hess CP, Phillips JJ, et al. Super-resolution track density imaging of glioblastoma: histopathologic correlation. AJNR Am J Neuroradiol 2013;34:1319-25 CrossRef Medline

10. Bozzali M, Parker GJ, Spanò B, et al. Brain tissue modifications induced by cholinergic therapy in Alzheimer's disease. Hum Brain Mapp 2013;34:3158-67 CrossRef Medline

11. Besseling RM, Jansen JF, Overvliet GM, et al. Tract specific reproducibility of tractography based morphology and diffusion metrics. PLoS One 2012;7:e34125 CrossRef Medline
12. Willats L, Raffelt D, Smith RE, et al. Quantification of trackweighted imaging (TWI): characterisation of within-subject reproducibility and between-subject variability. Neuroimage 2014;87: 18-31 CrossRef Medline

13. Pannek K, Mathias JL, Bigler ED, et al. The average pathlength map: a diffusion MRI tractography-derived index for studying brain pathology. Neuroimage 2011;55:133-41 CrossRef Medline

14. Calamante F, Smith RE, Tournier JD, et al. Quantification of voxelwise total fibre density: investigating the problems associated with track-count mapping. Neuroimage 2015;117:284-93 CrossRef Medline

15. Calamante F, Tournier JD, Kurniawan ND, et al. Super-resolution track-density imaging studies of mouse brain: comparison to histology. Neuroimage 2012;59:286-96 CrossRef Medline

16. Cho ZH, Calamante F, Chi JG. 7.0 Tesla MRI Brain White Matter Atlas. 2nd ed. Berlin: Springer-Verlag; 2015

17. Calamante F, Tournier JD, Smith RE, et al. A generalised framework for super-resolution track-weighted imaging. Neuroimage 2012;59: 2494-503 CrossRef Medline

18. Raffelt D, Tournier JD, Rose S, et al. Apparent fibre density: a novel measure for the analysis of diffusion-weighted magnetic resonance images. Neuroimage 2012;59:3976-94 CrossRef Medline

F. Calamante Florey Institute of Neuroscience and Mental Health Heidelberg, Victoria, Australia Florey Department of Neuroscience and Mental Health University of Melbourne Melbourne, Victoria, Australia Department of Medicine Austin Health and Northern Health, University of Melbourne Melbourne, Victoria, Australia

http://dx.doi.org/10.3174/ajnr.A4721 